\title{
Formação de docentes e currículos para além da resistência
}

NILDA GUIMARÃES ALVES

Universidade do Estado do Rio de Janeiro, Rio de Janeiro, RJ, Brasil

RESUMO

O artigo mostrou uma trajetória das práticas e do pensamento acerca da formação dos docentes no Brasil e seus currículos, indicando uma possibilidade histórica que foi além da resistência à agenda oficial. Nele, questionou-se uma posição comum em momentos de crise que é a de combate às posições oficiais, exclusivamente, indicando que é necessário e possível irmos além dessa resistência, sair da agenda imposta e propor movimentos diversos e criadores que possam produzir debates e avanços nessa - e em outras — questão.

PALAVRAS-CHAVE

formação docente; movimentos pela formação; redes educativas; resistência. 


\section{FORMATION OF TEACHERS AND CURRICULUMS THE BEYOND THE RESISTANCE}

\section{ABSTRACT}

This paper shows a trajectory of practices and thoughts regarding formation of teachers and the curricula they rely on in Brazil, depicting a historic opportunity that paved the way to outruning resistance to the official agenda. The study also questions a common position in moments of crisis: the exclusive struggle against official positions, indicating that going beyond resistance is necessary and possible, retreating from what is imposed and proposing various movements and creators that may produce debates and advances in this and other matters.

\section{KEYWORDS}

teacher education; movements for education; educational networks; resistance.

\section{FORMACIÓN DE DOCENTES Y CURRÍCULOS PARA MÁS ALLÁ DE LA RESISTENCIA}

\section{RESUMEN}

El presente artículo muestra una trayectoria de las prácticas y del pensamiento sobre la formación de los docentes de Brasil y sus currículos, señalando una posibilidad histórica que ha ido más allá de la resistencia a la agenda oficial. En el texto, es cuestionada una posición común en momentos de crisis que es la del combate a las posiciones oficiales, exclusivamente, indicando que es necesario y posible ir más allá de dicha resistencia, saliendo de la agenda impuesta y proponiendo movimientos diversos y creadores que puedan producir debates y avances en esta $-\mathrm{y}$ en otras - cuestión.

PALABRAS CLAVE

formación docente; movimientos por la formación; redes educativas; resistencia. 


\section{INTRODUÇÃO}

Há muito ${ }^{1}$ venho buscando compreender questões acerca de currículos, trabalhando com a formação de docentes em suas multiplicidades possíveis (Alves, 1996a, 1997, 1998a, 1998b, 2000, 2001, 2002a, 2002b, 2002c, 2006a, 2006b; Alves e Garcia, 2001). Desse modo, este artigo ${ }^{2}$ possui quatro partes. Na primeira, busco explicar questões teórico-epistemológicas importantes para a compreensão dos processos de pesquisa que desenvolvo dentro da corrente em que trabalho - a das pesquisas nos/dos/com os cotidianos, ${ }^{3}$ relativas a essa relação currículos-formação de docentes. $\mathrm{Na}$ segunda parte, trato do movimento organizado pelas mudanças curriculares dessa formação - desde 1983 na Comissão Nacional de Reformulação dos Cursos de Formação do Educador (CONARCFE), e desde 1990 pela Associação Nacional pela Formação dos Profissionais em Educação (ANFOPE). $\mathrm{Na}$ terceira parte, exponho a experiência de um curso de Pedagogia inovador, em Angra dos Reis, realizado pela Faculdade de Educação da Universidade Federal Fluminense (UFF). Na quarta, trabalho com o momento atual, com o que vejo de possibilidades para se ir além da crise que enfrentamos, baseadas nas experiências que vivi nos dois movimentos pensados nas partes dois e três deste artigo.

Espero mostrar, com isso, que a agenda dos docentes e pesquisadores pode tecer movimentos e produzir acontecimentos que vão além da simples resistência aos equívocos e mesmo imposições de eventuais políticas oficiais, considerando a resistência sempre necessária, é claro. Em outras palavras, em um momento de grande crise política do país, trago no texto dois movimentos que atuaram na formação de docentes - bastante relacionados um ao outro - e que permitem compreender que nunca são somente de resistência ao que é desenvolvido (e mesmo destruído) pela agenda oficial/governamental, mas que mostram a criação permanente de saídas outras, diferentes dessa agenda.

\section{ACERCA DE REDES EDUCATIVAS}

As pesquisas nos/dos/com os cotidianos que desenvolvo têm permitido indicar que formamos redes educativas múltiplas ${ }^{4}$ e que é nelas que nos formamos.

1 Meu primeiro texto sobre a questão é de 1982 e participei da reunião nacional de 1983, em Belo Horizonte, que foi referida e trabalhada neste artigo. Além disso, como diretora da Faculdade de Educação da Universidade Federal Fluminense (UFF), participei da proposta inovadora de formação docente que também foi discutida neste artigo.

2 Dedico este artigo a Regina Leite Garcia (in memoriam), companheira de muitas aventuras de formação docente.

3 As pesquisas que desenvolvo têm tido o financiamento do Conselho Nacional de Desenvolvimento Científico e Tecnológico (CNPq), da Coordenação de Aperfeiçoamento de Pessoal de Nível Superior (CAPES), da Fundação de Amparo à Pesquisa do Estado do Rio de Janeiro (FAPERJ) e da Universidade do Estado do Rio de Janeiro (UERJ) - e, antes de 1996, da UFF.

4 Inicialmente, as indiquei como "esferas" (Alves, 1998b), embora já admitindo a existência das redes, o que pode se perceber no título do livro referido. Em seguida, chamei-as de "contextos"; já aqui - e há algum tempo — entendendo-as como "redes de "práticasteorias" (Alves, 2010). 
Essas redes se caracterizam como de "práticasteorias' ${ }^{5}$ pois nela desenvolvemos processos educativos e os pensamos, continuamente. Até o presente, tenho podido trabalhar com as seguintes redes: a das 'práticasteorias' da formação acadêmica; a das 'práticasteorias' pedagógicas cotidianas; a das 'práticasteorias' das políticas de governo; a das 'práticasteorias' coletivas dos movimentos sociais; a das 'práticasteorias' das pesquisas em educação; a das 'práticasteorias' das manifestações artísticas; a das 'práticasteorias' de produção e 'usos' de mídias; e a das 'práticasteorias' de vivências nas cidades, no campo ou à beira das estradas. Essa ideia tem permitido uma compreensão mais complexa da formação e dos currículos uma vez que nos leva a entender o estabelecimento de processos, em uma e nos outros, tanto pelas relações entre os 'praticantespensantes' (Oliveira, 2012) de cada uma delas como das relações que se processam de cada uma com as outras.

Mais ainda: permitem compreender que os cursos de formação se apresentam como o grande articulador dos processos diferenciados de formação que se dão nas distintas redes.

Outro aspecto a observar quanto à existência dessas redes — exatamente pelas relações múltiplas de seus 'praticantespensantes' dentro delas e as estabelecidas entre elas - é que são 'espaçostempos' necessariamente políticos nos quais se fazem, se pensam e se criam políticas. Desse modo, compreendemos os 'espaçostempos' cotidianos como políticos e nos quais forças múltiplas e complexas estão permanentemente em disputa e negociações. É por isso que podemos indicar que as soluções encontradas são sempre complexas e múltiplas, incluindo inúmeros 'praticantespensantes'. Desse modo, para além de buscar compreender as políticas oficiais, seja de formação de docentes, seja quanto a currículos, pesquisando nos cotidianos escolares e com seus 'praticantespensantes' podemos entender os modos como se dão suas criações curriculares e de formação nos múltiplos e diferenciados 'espaçostempos' escolares. Esses movimentos nos têm mostrado que, para além de aplicar ou resistir, simplesmente, aos ditames oficiais acerca de currículos e de formação docente, existem propostas criativas nas escolas e em cursos de formação, bem como propostas de diversificadas forças sociais sobre essas questões que chegam às escolas e se trançam com as políticas oficiais existentes.

\section{MOVIMENTOS PELA FORMAÇÃO DOS DOCENTES}

No grande movimento pela democratização do país, no final da década de 1970 do século XX, foram incluídas lutas por mudanças pela Educação. A primeira reunião de educadores bastante significativa - pelo comparecimento de docentes de todos os níveis e pelos temas debatidos - foi o I Seminário de Educação Brasileira, em 1978, em Campinas, que se iniciou com uma gravação de uma conferência/mensagem de Paulo Freire, ainda fora do país. O seminário deu surgimento ao Centro de Estudos Educação e Sociedade (CEDES) que passou a publicar a Revista Educação e Sociedade. No mesmo

5 Múltiplos termos assim grafados — juntos, em itálico e entre aspas simples — que aparecem no texto mostram que temos entendido que as dicotomias, necessárias à criação do pensamento científico na Modernidade, têm significado limites ao que precisamos compreender nas pesquisas com os cotidianos. 
período, são organizadas: a Associação Nacional de Pós-Graduação e Pesquisa em Educação (ANPEd), cuja primeira reunião aconteceu em 16 de março de 1978, no Rio de Janeiro (Instituto de Ensino Superior Albert Einstein - IESAE/Fundação Getúlio Vargas), articulada pelos programas de pós-graduação em Educação existentes até então; e a Associação Nacional de Educação (ANDE), em São Paulo. Essas três organizações (CEDES, ANPEd e ANDE), juntamente com o Centro de Estudos de Cultura Contemporânea (CEDEC), iniciaram a realização das conferências nacionais da educação (Conferência Brasileira de Educação - CBEs: 1980/São Paulo; 1982/Belo Horizonte; 1984/Niterói; 1986/Goiânia; 1988/Brasília).

Toda essa grande movimentação, com intensificação de publicações — revistas, anais de congresso, livros (editoras da área começam a se fixar e produzir intensamente) - , traz sempre a presença da temática "formação de professores". Toda essa agitação leva o Ministério de Educação e Cultura (MEC) a propor uma discussão nacional pela formação; a proposta era "pensar um currículo para a formação de professores no Brasil”. Em cada estado brasileiro, em cada universidade e na maioria das secretarias estaduais aconteceram reuniões para discutir a questão. Durante os anos de 1982 e 1983 são realizados encontros regionais e, em novembro de 1983, é realizado o Encontro Nacional, que concluiria esse longo processo.

É preciso lembrar, ainda, que nesse momento a França criava, por todo o seu território o Institutos Superior de Educação e, em 1982, o MEC realizava, em Brasília, um colóquio ao qual comparecem franceses e brasileiros, em uma tentativa de indicar que esse seria também o "caminho a ser seguido no Brasil". ${ }^{6}$

Nesse Encontro Nacional, em 1983, contrariando as tentativas de condução oficial, respaldados por ampla discussão nacional, os representantes de todos os estados e do Distrito Federal - das diversas universidades e secretarias de educação - produzem um documento que analisa e propõe mudanças possíveis para todos os níveis do sistema de ensino, entendendo que devem ser pensados articuladamente. Esse documento nunca foi incorporado como orientador pelo MEC, mas, em contrapartida, foi o documento inicial para as ações da Comissão Nacional de Reformulação dos Cursos de Formação do Educador, que teve como sua primeira presidente Márcia Angela Aguiar e continuou a sê-lo quando a ANFOPE foi criada, tendo Luiz Carlos de Freitas como seu primeiro presidente (1990). Inúmeras são as indicações feitas e que poderia retomar neste artigo. No entanto, vou tratar somente de uma delas: a ideia de base comum nacional. Isso porque o entendimento que se teve da mesma naquele momento mostra o que quero indicar aqui: sempre é possível criar algo para além da simples resistência às propostas oficiais. Desde então, a ANFOPE vem realizando reuniões anuais periódicas, enfrentando a questão da formação docente. ${ }^{7}$

6 Essa indicação teve influência de Darcy Ribeiro, que possuia contatos na França, de onde voltara do exílio havia pouco.

7 Gostaríamos de lembrar, ainda, além dos nomes já citados no texto, nomes de importância para a manutenção nacional desse movimento: Leda Scheibe, Helena de Freitas e Íria Brzekiski. Eu também cheguei a presidir a ANFOPE, no início dos anos 1990. 
No documento de 1983, quando pensada a formação docente, foi criada a ideia de possibilitar a existência de uma base comum nacional, para a qual é explicitada uma metodologia de trabalho. Acompanhando experiências que vinham sendo realizadas em poucas universidades - a Universidade Federal de Goiás (UFG) foi uma delas e a ela dedicamos diversos debates, naquele momento - indicava-se que essas instituições deveriam propor currículos diversos, em acordo com seus docentes e discentes e com ampla relação com as questões regionais; também deveriam ser organizadas reuniões regionais e nacionais para discuti-las, o que foi efetivamente realizado pela CONARCFE e pela ANFOPE, como já comentamos. O acúmulo dessas experiências e o debate em torno delas permitiriam o aparecimento, aos poucos, de ideias comuns acerca de currículos da formação docente. Ou seja, a possibilidade de vir a ser "nacional" só ocorreria após o surgimento de ideias "comuns" a partir dos debates em torno dessas diversas experiências necessárias, em sua diversidade, e do estabelecimento de ideias, em comum, acerca do que é possível na formação.

No entanto, entendendo a complexidade da escola e a diversidade dos processos curriculares das tantas escolas por este imenso país, havia uma ideia comum já na partida e que está no Documento de 1983: o magistério é a base da formação. ${ }^{8}$ Todos aqueles profissionais que podem ser envolvidos nos processos escolares precisariam ter, inicialmente, uma formação para a docência que lhes permitiria compreender a complexidade e diversidade dessas questões. De algum modo, já nesse momento — no qual, com ideias mais uma vez importadas, autoridades educacionais criavam diversos profissionais que "deveriam" estar nas escolas (supervisores, orientadores, psicólogos, inspetores, avaliadores, em uma variedade de nomes e funções) — se buscava garantir que o articulador do processo era/precisa ser o/a docente. Essa, inquestionavelmente, foi a ideia central que uniu o movimento desde aí.

Ao mesmo tempo discutia-se, nos movimentos sociais e no Congresso, a lei que nos daria as diretrizes e bases da educação. Os movimentos sociais se articularam em torno do substitutivo que recebeu o nome do deputado Jorge Hage. Em um determinado momento, o Senador Darcy Ribeiro apresenta, na outra casa legislativa, outro projeto. Isto gera uma enorme celeuma, muito bem descrita e resumida em artigo de Otranto (1996), ainda à disposição dos leitores na internet. Esse texto nos permite lembrar o rude golpe sofrido pela proposta discutida e gerada no movimento, com adesão de diversos parlamentares e o papel que o então senador Darcy Ribeiro teve ao não aceitar ouvir o que os movimentos trouxeram de indicações possíveis de mudança para a educação brasileira. O texto de Otranto referido caracteriza as grandes polêmicas do período e a presença dos movimentos sociais nelas, mostrando o quanto de luta, resistência e criação existiram naquele momento no sentido de defender o que tinha sido proposto e organizado nos projetos do deputado Otávio Elísio e do deputado Jorge Hage, que apresentou substitutivos ainda articulados com as sugestões advindas dos movimentos sociais. Nele, escreve Otranto (1996, p. 1):

8 Essa ideia vai aparecer na Lei no 9.394/1996, no parágrafo único do art. 67, no qual podemos ler: "A experiência docente é pré-requisito para o exercício profissional de quaisquer outras funções de magistérios nos termos das normas de cada sistema de ensino". 
Com a promulgação da Constituição de 1988, por iniciativa do então deputado Otávio Elíseo, foi apresentado na Câmara dos Deputados um Projeto de LDB. Este projeto (1.258/1988) refletia as discussões que já estavam ocorrendo no Brasil em diferentes Congressos, Encontros, Simpósios, Seminários (...), que reuniam entidades representativas do setor educacional. A Comissão de Educação da Câmara realizou então, 40 audiências públicas, para a discussão do Projeto. Em agosto de 1989 surgiu o $1^{\circ}$ Substitutivo do deputado Jorge Hage que incorporou 13 projetos parlamentares e as discussões realizadas nas audiências. No segundo semestre de 1989 as discussões para o aprofundamento do tema aconteceram na forma de Simpósios Temáticos. Em fevereiro de 1990 surgiu, então, o 2 Substitutivo Jorge Hage que incorporou 978 emendas e mais de 2.000 sugestões da sociedade civil organizada. Este Substitutivo foi ao Plenário da Câmara em 1991, onde recebeu 1.263 emendas e retornou às Comissões de Educação, Justiça e Finanças, buscando, em sua forma, refletir os anseios educacionais da sociedade brasileira. Em 1992, começou a ser comandado, por parlamentares ligados ao governo do então presidente Fernando Collor, um processo de obstrução ao Projeto de LDB que tramitava, democraticamente, na Câmara dos Deputados.

Esse trecho do referido artigo mostra como, naquele momento, os diálogos com parlamentares permitiram grande participação e a criação de inúmeras propostas e como o processo foi interrompido no governo Collor.

No entanto, a grande obstrução foi efetivamente criada quando, na descrição ainda de Otranto (1996, p. 1-2):

O Senador Darcy Ribeiro, junto com o então Senador Marco Maciel e, com a aprovação do MEC, apresentou um novo Projeto de LDB, no Senado Federal, desconsiderando o trâmite do Projeto original, na Câmara dos Deputados. Após o "impeachment" do presidente Fernando Collor, o então Ministro da Educação Murilio Avelar Hingel se pronuncia a favor do Projeto em tramitação na Câmara que, agora tendo como relatora a deputada Angela Amim, é aprovado naquela Casa, no dia 13/05/93. Ao dar entrada no Senado Federal, o Projeto oriundo da Câmara (PLC) recebe o no 101/93 e seu Relator, Senador Cid Sabóia, inicia o processo de discussão com a realização de audiências públicas e recebimento de emendas. Após amplos estudos e discussões o Senador Cid Sabóia teve seu Parecer, de n²50, aprovado em novembro de 1994, na Comissão de Educação do Senado, apresentando um substitutivo que mantém as linhas diretrizes do PLC 101/93 originário da Câmara. O mesmo foi incluído na Ordem do Dia do Senado em 30/01/95, mas não houve “quorum" para a sua apreciação no Plenário. Em 17/03/95, através de uma manobra regimental, o Substitutivo Cid Sabóia, que deveria ir ao Plenário, retorna às Comissões de Educação e de Justiça e Cidadania, e é considerado inconstitucional, através do Parecer do Senador Darcy Ribeiro, Relator nas duas Comissões.

Estes processos, no Senado, criaram enorme confusão: a qual desses tantos projetos se deveria apresentar emendas? Embora, o então presidente do Senado - 
José Sarney - tenha decidido que devessem ser apresentadas ao PLC no 101/93, originado da Câmara dos Deputados, Otranto (1996, p. 3) lembra que:

o Senador Darcy Ribeiro, ao apreciá-las, toma como referência o seu próprio Substitutivo, desrespeitando as "Questões de Ordem" levantadas pelos Senadores Jader Barbalho e Emília Fernandes. Apesar de todas as irregularidades, o Senador Darcy Ribeiro, como Relator da Comissão de Educação consegue aprovar o PLC 101/93, mas, na forma do seu Substitutivo. Votando, ainda, em seu Parecer, pela prejudicialidade do Substitutivo Cid Sabóia, bem como do PLC 45/91, onde havia, anteriormente, apensado o seu Projeto.

Otranto (1996) reflete, então, os sentimentos de todos os que participaram dos movimentos, dizendo:

Assistimos, então, perplexos, a um confronto inusitado, entre um Projeto que é fruto de seis anos de amplos debates, que, se não é o ideal de todos, pelo menos, traduz as reivindicações de muitos, com outro de autor único, que só recentemente se submeteu a pouquíssimos debates, apenas sob grande pressão de outros parlamentares e dos segmentos organizados da sociedade civil. O Substitutivo Cid Sabóia e o PL 101/93 guardam características semelhantes, pois um foi originário do outro e possuem a mesma linha diretriz. O Substitutivo Darcy Ribeiro, por sua vez, apresenta uma proposta diametralmente oposta às demais. (Otranto, 1996, p. 3)

Desse modo, é aprovado o que foi nomeado pelos movimentos como "substitutivo Darcy Ribeiro VI", transformado na Lei no 9.394, de 20 de dezembro de 1996, que cria as bases e diretrizes da educação nacional.

Para discutir nossa questão neste artigo — relação da formação docente-currículos - pareceu-me necessário mostrar tal contexto para compreendermos a força da formulação da ideia de base comum nacional pelo movimento, uma vez que ela é mantida, nessa Lei, quando se fala da formação docente, embora em uma proposta que nada tem a ver com a do movimento, aparecendo modificada quando se refere aos currículos da educação básica. Aí ela vai aparecer como: base nacional comum.

Como a "nossa" base era pensada em um permanente movimento de articulação e debates, essa outra formulação (que se afirma nacional antes de se entender comum) pareceu-nos autoritária e os movimentos se colocaram contra ela. A todas as tentativas de fazê-la vir à luz, em especial como indicação para os testes nacionais que foram sendo implantados, autoritariamente - e, como sempre, importados de alguma experiência externa - no governo de Fernando Henrique Cardoso, tendo como Ministro de Educação, Paulo Renato Souza, os movimentos e as entidades da área existentes foram se colocando contra. A primeira dessas tentativas foi a produção e a intensa divulgação dos chamados "Parâmetros curriculares nacionais". Os movimentos responderam a isto, mais uma vez de forma criativa, iniciando, junto ao Conselho Nacional de Educação, a extensa produção de diretrizes que atendiam a todos os graus e modalidades de ensino. Entendíamos que, se a lei era de "diretrizes e bases", era necessária a formulação das primeiras, antes de tudo. 
Quando, a partir da Lei no 13.005 , de 25 de junho de 2014 - cujo processo não discutiremos aqui - surge oficialmente o Plano Nacional de Educação (PNE) um poderoso movimento de fundações privadas diversas reaparece para tentar implantar um sistema unificado de ensino que lhes permitisse ampliar o processo de "apostilagem" ${ }^{\text {do }}$ mesmo, o que thes abriria um canal largo para a venda de material, planos e cursinhos para docentes e diretores às secretarias municipais e estaduais, continuando um processo que já tinham iniciado antes. As entidades da área (ANPEd, CEDES, ANFOPE, Associação Brasileira de Currículo - ABdC, e outras), algumas com representação no Fórum Nacional de Educação (criado pela Lei), começaram a se pronunciar contra sua precipitada implantação sem nenhuma metodologia especial de discussão e sem sequer se referir às diretrizes existentes e que deveriam servir de base a qualquer debate da questão. ${ }^{10}$ Inúmeros artigos foram publicados acerca desse processo; destacamos os dossiês organizados pela $\mathrm{ABdC}$ nas revistas: Teias (Universidade do Estado do Rio de Janeiro - UERJ), E-Curriculum (Pontifícia Universidade Católica de São Paulo PUC-SP) e Currículo sem Fronteiras (Universidade Federal de Pernambuco - UFPe). Deles, queremos indicar para leitura, especialmente, dois: Dias e Ponce (2015) e Macedo e Sussekind (2014). Os textos desses dossiês e tantos outros, para além de combate ao processo oficial de implantação, agravado pelo golpe de 2016, oferecem caminhos para um mais amplo debate dessa relação formação docente-currículos. Ou, em outras palavras, os artigos neles incluídos, além de resistência aos processos em curso, indicam possibilidades de criação curricular, com base em múltiplas pesquisas e experiências.

\section{UMA EXPERIÊNCIA EM FORMAÇÃO DE DOCENTES}

No movimento de desenvolver experiências e levá-las ao debate coletivo em reuniões regionais e nacionais, desenvolvido pela ANFOPE, a Faculdade de Educação da UFF, a partir de um curso de extensão no município de Angra dos Reis ${ }^{11}$ recebeu do governo municipal recém-eleito, que foi o primeiro governo do PT no estado do Rio de Janeiro, a proposta de fazer um curso de Pedagogia no município. Outras propostas foram feitas à Faculdade por outros municípios, mas a decisão favorável se deu mesmo para que se realizasse em Angra dos Reis, pelos seguintes motivos:

1. o município realizava muitos concursos públicos para docentes nos diversos graus e modalidades e em todas as disciplinas;

9 Esse foi o termo encontrado pelos pesquisadores e entidades para caracterizar o movimento que se desenvolvia pela produção e venda de "manuais", bastante reduzidos, que essas fundações estavam repassando, em especial, aos municípios.

10 Lembremos que, recentemente (junho/2017) as entidades que formavam o Fórum, em oposição à sua desfiguração pelo MEC atual, saem do mesmo e iniciam um movimento de organizarem a reunião periódica dos movimentos, prevista na referida Lei, independente do Fórum "controlado".

11 O curso foi dado por Luiz Carlos Manhães, Angela Siqueira e Gelta Xavier, em 1990. Os três participaram da Comissão de Formulação Curricular do Curso de Pedagogia da UFF em Angra dos Reis, em 1991, junto com Regina Leite Garcia e Nilda Alves. Pela Prefeitura de Angra participaram o secretário municipal de Educação (Francisco Potiguara) e a vice-secretária (Maria Teresa Paliologo de Brito). 
2. era, então, o melhor salário para professor no estado;

3. o secretário e a vice-secretária de Educação aceitaram organizar e financiar uma reunião por semana de uma comissão para criação do curso em regime experimental, que aconteceu, em semanas sucessivas, na Faculdade de Educação da UFF, em Niterói, e na Secretaria de Educação, em Angra dos Reis, durante todo o ano de 1991.

A proposta foi se articulando em torno da possibilidade de se ter um regime experimental, garantido na LDB/71 em que se podia ler: "Art. 64. Os Conselhos de Educação poderão autorizar experiências pedagógicas, com regimes diversos dos prescritos na presente Lei, assegurando a validade dos estudos assim realizados". ${ }^{12}$ Além disso, buscava aplicar uma ideia que se transformava em consenso de que os docentes deveriam, todos, ser formados no nível superior.

A possibilidade de regime experimental, estimulada pelo documento de 1983, não tinha ainda sido usada em nenhuma proposta até então. A ideia de trazê-la nesse curso abriu condições para a sua realização, considerando o contexto possível:

- os docentes da UFF, cuja sede está em Niterói (RJ), precisariam se deslocar a cada semana para o município de Angra dos Reis, em viagens de pelo menos três horas de ida e três de volta;

- esses docentes continuavam a dar aulas em Niterói, o que exigia um equacionamento de dia da ida a Angra dos Reis;

- o curso deveria ser noturno (das 18 às $22 \mathrm{~h}$ ) para atender aos docentes do município e municípios vizinhos que trabalhavam durante o dia, e isso exigia que os docentes da UFF, que para aí se deslocassem, dormissem em Angra;

- uma série de questões que se acumulavam acerca da formação de docentes - e que estavam sendo discutidas no movimento - poderia ser resolvida se buscássemos um currículo efetivamente inovador, em torno dos eixos curriculares que eram indicados pelo movimento: relação teoria-prática; sólida fundamentação teórica; compromisso social e democratização da escola e dos conteúdos; trabalho coletivo e interdisciplinar; escola e individualidade.

No limite desse artigo, trago apenas alguns aspectos do que foi proposto e desenvolvido no curso em Angra dos Reis pelo que tinha de inovador. Inicio com a estrutura do mesmo, entendida como em redes e compreendendo vários

12 O regime experimental sempre foi permitido nas sucessivas LDBs. A Lei no 4.024/1961 indica, em seu art. 104: "Será permitida a organização de cursos ou escolas experimentais, com currículos, métodos e períodos escolares próprios, dependendo o seu funcionamento para fins de validade legal da autorização do Conselho Estadual de Educação, quando se tratar de cursos primários e médios, e do Conselho Federal de Educação, quando de cursos superiores ou de estabelecimentos de ensino primário e médio sob a jurisdição do Governo Federal”. Como esse artigo não fora anulado pela Lei de 1971 foi, também, sustentado no surgimento da proposta, já que era mais abrangente. Já a Lei no 9.394/1996 indica em seu art. 81: "É permitida a organização de cursos ou instituições de ensino experimentais, desde que obedecidas as disposições desta Lei”. 
elementos e se desenvolvendo de modo espiralado, como mostra a Figura 1 (Alves e Garcia, 2001, p. 81):

Essa imagem, reproduzida de artigo em livro que já se encontra em sua $11^{\mathrm{a}}$ edição, foi produzida pelas autoras do mesmo após ampla discussão dentro da Comissão de Formulação do Curso e nas instâncias oficiais da UFF, do Colegiado de curso ao Conselho Superior de Ensino, Pesquisa e Extensão (CSEPE). Reflete, por um lado, aquilo que até aquele momento tinha sido debatido no movimento (já na ANFOPE) e o que foi pensado pelo conjunto de docentes da Faculdade de Educação. No artigo, é assim explicitada:

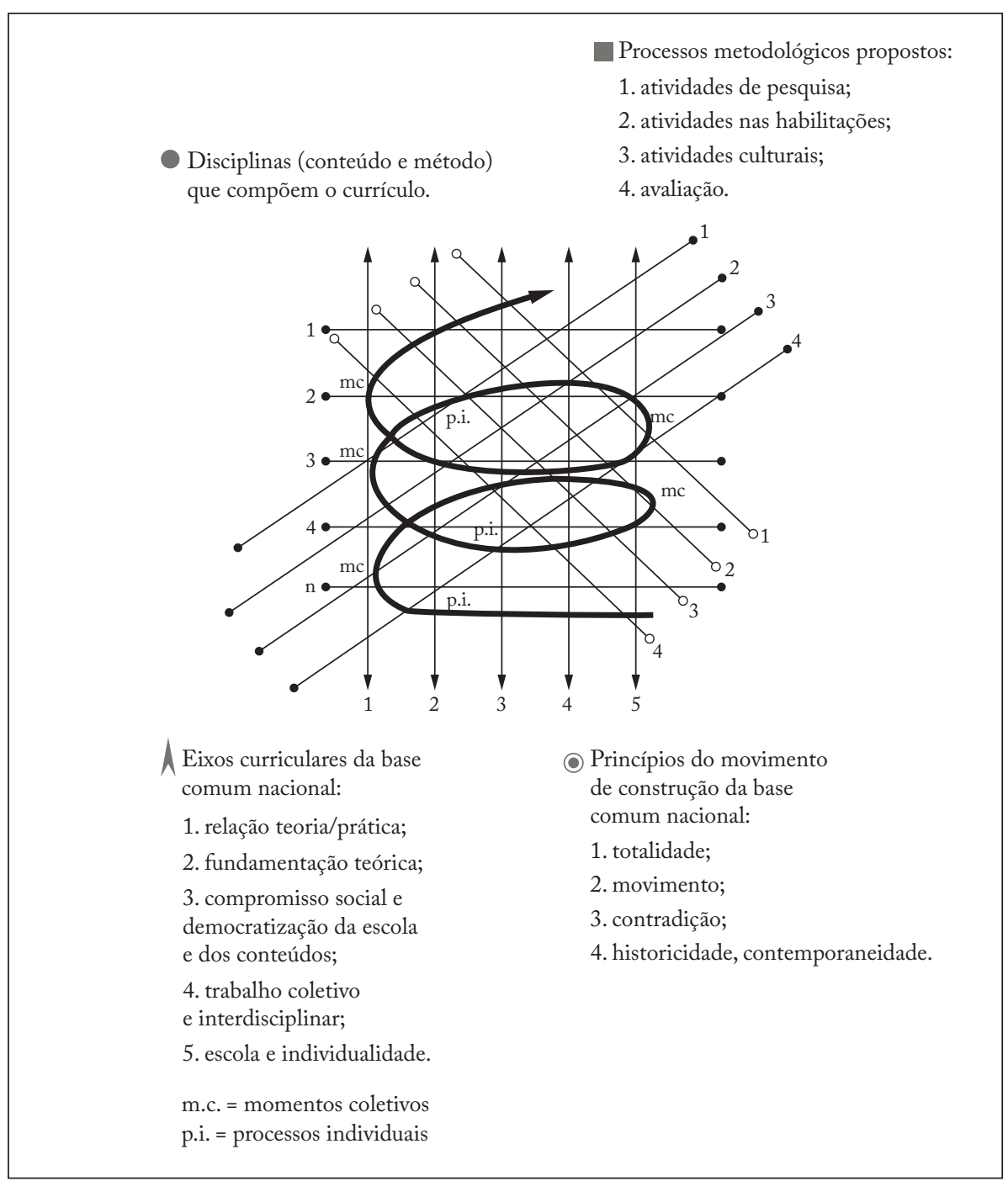

Figura 1 - Estrutura do curso da UFF em Angra dos Reis 
A proposta curricular elaborada assume, então, que o processo de conhecimento, bem como o caminho curricular, se dá não linearmente, mas como uma espiral aberta, na qual a tensão é constante entre disciplinas e atividades, na construção das múltiplas relações, entre individualidades e coletivos, e pelos vários trajetos realizados do particular ao geral e deste, novamente, ao particular, com a mediação dos específicos (as habilitações) (Alves e Garcia, 2001, p. 81-82).

Esses tantos componentes e as ações que neles eram realizadas foram organizados em um aglutinador curricular a que se deu o nome de Núcleo de Estudos e Atividades Pedagógicas (NEAP). Cada NEAP correspondia a um período do curso e possuía: três disciplinas - que ocupavam, no horário semanal, três dias; o componente Pesquisa e Prática Pedagógica (PPP) - que ocupava a quarta-feira, e no qual os estudantes se distribuíam em temáticas pelas quais optavam; e estudos dirigidos - que ocupavam a quinta noite da semana. Esses estudos dirigidos eram necessários no entendimento de que os estudantes - em sua grande maioria, trabalhadores - precisavam de tempo e de orientação para a leitura que deveriam realizar acerca dos textos debatidos nas disciplinas, em um tempo especial, com um professor específico. Os seminários de avaliação e planejamento dos períodos eram realizados a cada dez semanas, na sexta à noite e no sábado, manhã e tarde, com a participação dos docentes que tinham atuado no NEAP que acabara e daqueles que participariam do que começaria, bem como de todos os estudantes.

Esses NEAPs tinham também, como dizíamos, "nome e sobrenome", ou seja, possuíam um título e uma explicitação/ementa do que seria desenvolvido. Reproduzimos aqui os mesmos, para melhor especificar esse grande processo criativo, embora reconhecendo sua datação, inclusive quanto ao que hoje precisamos fazer:

1. Educação e sociedade:

- análise de estrutura e conjuntura e suas relações;

2. Educação, história e conhecimento:

- o processo histórico de construção coletiva do conhecimento e a privatização deste;

3. Visões de mundo e o ensino das ciências:

- a ciência como espaço de disputa e a importância da socialização do conhecimento científico;

4. Educação popular e trabalho:

- o papel central do trabalho na história dos homens e a apropriação privada dos seus resultados;

5. Alfabetização e linguagens:

- a apropriação de diferentes linguagens como possibilidade de acesso ao conhecimento e de afirmação de um discurso autônomo;

6. A construção cotidiana da escola:

- o conflito entre o público e o privado na escola e a reorientação curricular;

7. O cotidiano da escola e da sala de aula:

- a escola com espaço possível de construção de novas relações e novos saberes; 
8. Práxis pedagógica I:

- a teoria e a prática no ensino fundamental;

9. Práxis pedagógica II:

- a teoria e a prática no ensino fundamental;

10. Práxis pedagógica III:

- a teoria e a prática dos profissionais da educação;

11. Práxis pedagógica IV (por habilitação):

- o cotidiano do ensino fundamental;

- o cotidiano da pré-escola;

- o cotidiano da Escola Normal;

- o cotidiano da administração escolar;

- o cotidiano da supervisão escolar;

- o cotidiano da orientação escolar;

12. Pesquisa;

13. Atividades culturais (Alves e Garcia, 2001, p. 83-84).

Para a pesquisa e as atividades culturais não foram produzidas emendas porque reconhecíamos a necessidade de serem trabalhadas diferentemente. Quanto às atividades de pesquisas, foram alocadas na quarta-feira e os docentes responsáveis por seu desenvolvimento apresentavam as temáticas que queriam desenvolver, bem como as metodologias que entendiam importantes. Assim, tivemos como temas, por exemplo: educação ecológica; formação de professores; tecnologias educacionais; linguagens; avaliação; 'espaçostempos' de formação 'dentrofora' das escolas; processos culturais; juventude e grupos juvenis etc. Os estudantes escolhiam o grupo do qual queriam participar, com o orientador desse que se transformava em orientador de monografia dos mesmos no final do curso.

As atividades culturais foram realizadas, também, de maneiras muito diferentes: idas organizadas a outras cidades ou na própria cidade de Angra e seus entornos (praias; usina atômica; montanhas; caminho do ouro; comunidades locais) para: pesquisa de campo (criação de mapas e roteiros; coleções de animais e vegetais; álbuns de fotografias); visitas a museus ou outras instituições; assistir a diversos espetáculos; caminhadas com organização de roteiros. Também aconteciam em semanas que eram colocadas entre NEAPs durante as quais se trazia artistas, escritores, pesquisadores, militantes de movimentos etc., para Angra. Muitas atividades foram realizadas em torno de acontecimentos, artistas e militantes de movimentos no próprio município em toda a região da Costa Verde, no litoral sul do estado do Rio de Janeiro.

Assim, outro aspecto a destacar foi a compreensão de que o currículo da formação ia além daquilo que institucionalmente se denominava "disciplina". Essa denominação precisava aparecer para a aprovação oficial do curso, mas era limitada em relação ao que realmente estava presente nele. Assim, começamos a usar a ideia de "componente curricular"; pois, como chamar de disciplina as "atividades culturais" ou os seminários de avaliação e planejamento dos períodos do curso que compunham créditos e horários? É possível reconhecer como disciplina um componente criado e que foi chamado PPP? Esse, entendíamos, tinha a ver com a 
compreensão de que a formação se dá pela articulação de diversas redes educativas ${ }^{13}$ que desenvolvemos e nas quais nos formamos com outros, em processos complexos e diferenciados, nos tantos 'dentrofora' das escolas.

Por fim, é necessário dizer que a articulação do curso era também mantida, por uma reunião dos docentes da Faculdade de Educação, todas as segundas-feiras das 9 às $12 \mathrm{~h}$. Nela, dúvidas eram discutidas, problemas resolvidos, atividades decididas, discussões eram travadas, percorríamos processos de negociação diversos etc. Das questões muito discutidas - e quando se sentiu a presença de autoridades da UFF que se colocavam contra essa experiência - uma foi acerca da avaliação das atividades culturais: exigir algo escrito (relatório) de cada atividade feita? Por quê? Se cultura é fruição - é assim que a vivemos em todas as redes — por que quando realizada dentro de um currículo escolar precisa de algo escrito e de sua avaliação? Decidiu-se que não haveria nada escrito. Conversas com docentes, registros orais durante os seminários de avaliação e planejamento, sim. Mas como registrar notas, já que era uma "disciplina" do currículo do curso? Inicialmente decidimos fazer do mesmo modo como notificávamos presença e ausência nas disciplinas: $\mathrm{S}$ (suficiente); I (insuficiente). A administração central não admitiu essa solução porque "os computadores não aceitavam" - ah! esses artefatos dotados, espantosamente, de decisão! Demos então outra solução: 10 ou $0 .$. Ainda se tentou não aceitar isso porque - como praticamente todos os estudantes tinham 10 , já que participavam intensamente dessas atividades - isso aumentava muito o exponencial de rendimento do curso de Angra "prejudicando" os outros cursos... Mas essa solução foi adotada.

Desse modo, buscando colocar em ação aquilo que o movimento vinha tecendo desde 1983 e enfrentando fortes dificuldades internas, o curso foi desenvolvido com essa proposta durante dez anos, indicando possibilidades que foram incorporadas em outras experiências. A primeira delas foi o Curso de Pedagogia da Faculdade de Educação (UFF), em Niterói, que em contexto bem diferente com inúmeras turmas já em andamento, com a totalidade de docentes da faculdade, sem a necessidade de viagens longas e cansativas etc. - fez também uma mudança significativa em seu currículo oficial, considerando essas e outras diferenças.

\section{O MOMENTO PRESENTE, A POSSIBILIDADE DE RESISTIR E A NECESSIDADE DE IR ALÉM DA RESISTÊNCIA}

Creio que os dois exemplos discutidos até aqui permitem que pensemos a possibilidade de resistir a este momento difícil no Brasil e no mundo, no campo educacional e em tantos outros e, ainda, pensar como esses dois exemplos mostram que processos coletivos podem ser estabelecidos - de praticar e pensar, portanto, de criar - levando a que encontremos caminhos de transformação mesmo na crise (Certeau, 1998).

13 Inicialmente, consideramos a ideia de "esferas de formação" (Alves, 1996a), na época da organização da proposta a que nos referimos. Em seguida, usamos "contextos de formação" (Alves, 2010). Por fim, atualmente, usamos "redes educativas de "práticasteorias", que explicitamos no início deste artigo. 
Comecemos por lembrar que, no primeiro ano do segundo mandato da presidenta Dilma Roussef (2015), o Conselho Nacional de Educação concluiu um longo processo de estabelecimento das Diretrizes Curriculares Nacionais para a Formação Inicial e Continuada dos Profissionais do Magistério da Educação Básica, com o Parecer $\mathrm{n}^{\circ} 2 / 2015,{ }^{14} \mathrm{em} 9$ de junho de 2015, homologado com o despacho ministerial e publicado no Diário Oficial da União de 25 de junho de 2015. Podemos dizer, sem erro, que ele contém um bom número de medidas que vêm do documento de 1983, discutidas, melhoradas e atualizadas, dentro no movimento desde então.

Não creio que caiba, no limite deste artigo, uma longa análise desse documento. No entanto, vou me referir a alguns aspectos que permitem compreender esse processo e meu argumento principal: podemos ir além da resistência política aos atos oficiais contrários ao que os movimentos e nossas pesquisas vêm acumulando, criando possibilidades de outros processos.

Um desses elementos, dessas Diretrizes, que considero poderoso para buscarmos novos caminhos está no modo como integra a formação de docentes, pois pensa em conjunto todas as licenciaturas, bem como a graduação e a pós-graduação. No primeiro caso, pode permitir a criação de componentes curriculares comuns como, por exemplo, planejamento pedagógico (curricular e didático) que se dê em torno de como 'fazerpensar' juntos discentes das diversas licenciaturas, propostas curriculares para anos ou ciclos de ensino. Outro exemplo, ainda, seria termos um componente que permitisse, em conjunto, ações 'dentrofora' das escolas como: idas a museus, parques, exposições; organização de colóquios, seminários, cineclubes; criação de material didático articulado on-line ou para ensino presencial; estudos do meio; escrita de livros sobre temática comum e que interessasse às diversas disciplinas; e tudo aquilo que nossa capacidade docente e discente permitisse criar em conjunto, fugindo da solidão da formação em cursos extremamente isolados como temos no presente. Por que isto é importante: porque, simplesmente, esse é o modo como devem ser desenvolvidos os currículos escolares. Com muito maior articulação disciplinar, em relação a problemas a serem enfrentados por todos nós, na contemporaneidade.

Quanto à articulação graduação-pós-graduação, temos aqui a compreensão de que a formação do docente é contínua e complexa. Deve se dar sempre, e não só em um curso de graduação. A imensa quantidade de docentes que buscam cursos de pós-graduação, seja lato sensu, seja stricto sensu, há muito tempo, mostra que eles/elas sabem disso, desde sempre, mesmo sem apoio oficial para frequentarem esses cursos, na maioria das vezes. Por outro lado, essa ideia possibilita pensar a graduação de forma mais articulada e compacta, sem perder a qualidade, em torno de elementos como: carga horária; dias ocupados; articulação disciplinar; e 'espaçostempos' de estudo e de práticas (presenciais e on-line), por exemplo. Pensados em conjunto, pelos docentes dos cursos de licenciatura, esses elementos permitem avançar significativamente de forma bem mais dinâmica que no momento atual.

14 Lembrar que a comissão responsável tinha representantes do movimento que vinham desde 1983, e que destaco em itálico: José Fernandes de Lima (presidente), Luiz Fernandes Dourado (relator), Antonio Carlos Caruso Ronca, Francisco Aparecido Cordão, Gilberto Gonçalves Garcia, José Eustáquio Romão, Luiz Roberto Alves, Malvina Tania Tuttman, Márcia Angela da Silva Aguiar, Raimundo Moacir Mendes Feitosa e Sérgio Roberto Kieling Franco. 
Com isso, muitos de nós se liberariam para oferecer cursos de pós-graduação lato sensu na quantidade, há muito, exigida por docentes da educação básica e com a qualidade necessária.

Sei muito bem que esses exemplos contrariam, e muito, nossa "tradição" acadêmica de formação. Mas eu os trago para mostrar que são exemplos que podem - e, em minha opinião, devem - expandir-se em tempos de crise, pois, para serem tecidos, precisam apenas dos nossos 'praticantespensantes' internos: docentes, estudantes, conselhos superiores e reitoria. Difícil articulação? Muitas vezes sim, mas permitindo amplo movimento de criação interna, o que nos potencializa para as muitas lutas e negociações necessárias, para fora.

\section{À GUISA DE CONCLUSÃO}

Resistir é necessário; viver exige muito mais: exige criação!

Desse modo, as posições que defendo neste artigo não significam que considere que tenhamos que ser otimistas sempre ou que a possibilidade de fazer algo existe continuamente. ${ }^{15}$ Não! Mas experiências anteriores e as investigações que desenvolvo dentro da corrente de pesquisas com os cotidianos permitiram compreender que somos capazes nos processos de formação - e em todos os processos de Educação - de "sentir" as necessidades existentes e as possibilidades de ação em contextos os mais difíceis. E criar reunindo forças próximas e realizando mudanças locais, com apoio em pontos da legislação existente.

As conquistas realizadas, até o presente, precisam ser defendidas e as mudanças extremamente reacionárias que tentam implantar, em nosso campo de atuação, exigem muita articulação e fortes processos de resistência. Tudo isto nos faz gastar imensas forças. Como nos potencializar para mais lutas e negociações? Criando! Para isso, precisamos pensar as possibilidades locais, institucionais, aquelas forças com as quais poderemos compor para criar movimentos potentes.

Avaliar, entre as mudanças indicadas pelas Diretrizes, quais delas contribuiriam para movimentar as forças que desejamos/podemos mobilizar.

Ao resistirmos às mudanças que as forças retrógadas desejam implantar estamos combatendo no campo delas. Criar outros caminhos permite lutar dentro de agendas que são nossas.

Reconheço que, após um movimento que entendemos ser um golpe político diferente do que conhecíamos até o presente - é preciso desenvolver alguns movimentos pessoais e coletivos diversos daqueles que processávamos até então. Isso exige 'espaçostempos' também outros que temos visto aparecer aqui e ali: a ocupação de parte da Avenida Paulista, na cidade de São Paulo, por membros do Movimento dos Sem-Teto (MST); a movimentação de docentes e discentes nas universidades estaduais, como na UERJ (abraço a UERJ); ciclo de palestras; recusa, até agora, de seus docentes de fazerem greve mesmo vendo que a situação material da universidade está profundamente deteriorada; posição da Reitoria, que se recusou a começar o ano letivo sem que estas

15 A situação pela qual passa a UERJ (e tantas outras universidades estaduais) no presente não me permite tal ilusão! 
condições estivessem minimamente resolvidas etc.; a ocupação de escolas públicas por seus estudantes, em diversos estados, com reivindicações múltiplas. Tudo isso pode servir de exemplo. Em todos os casos, para além de processos de resistência, vimos aparecer indicações de mudanças necessárias. Mas sabemos que é preciso muito mais.

Criar exige continuidade e negociações que permitam fazer aparecer algo sólido e estimulante, que aglutine forças e desenvolva potencial naqueles que dele participam. Só algo assim nos fará criar uma agenda própria que nos permita ir adiante, na profunda crise em que vivemos.

As pesquisas com os cotidianos nas diversas universidades em que se desenvolvem nos permitem perceber que certas ações, anteriores ao atual processo golpista, continuam a se realizar: escolas, movimentos e redes educativas que continuam a discutir a necessidade de respeito às diversas religiões e à existência de gêneros diferentes no âmbito escolar, e de lutar contra racismos, homofobias, discriminações de todo o tipo. Os processos de normatização que vêm aparecendo, entre eles o "escola sem partido", por exemplo, têm encontrado resistência também nesses cotidianos, tanto como nos das diversas redes educativas nas quais docentes se formam.

Nessa situação mundial de recuo dos tantos direitos de viver, os movimentos locais continuam desafiando e buscando saídas solidárias. Tenhamos olhos para vê-los, coração para senti-los e pensamento para compreendê-los.

\section{REFERÊNCIAS}

Alves, N. A experiência da diversidade no cotidiano e suas consequências na formação de professoras. In: Victorio Filho, A.; Monteiro, S. C. F. (Orgs.). Cultura e conhecimento de professores. Rio de Janeiro: DP\&A, 2002a. p. 13-29.

. A formação da professora e o uso de multimeios como direito. In: FiLÉ, V. (Org.). Batuques, fragmentaçôes efluxos. Rio de Janeiro: DP\&A, 2000. p. 25-40.

. A formação de professores na lei e para além dela. In: Silva, W. C. da (Org.). Formação dos profissionais da educação: o novo contexto legal e os labirintos do real. Niterói: EdUFF, 1998a. p. 75-91.

. Artefatos tecnológicos relacionados à imagem e ao som na expressão da cultura de afro-brasileiros e seu "uso" em processos curriculares de formação de professoras na educação superior - o caso do curso de pedagogia da UERJ/Campus Maracanã. In: Amorim, A. C. R.; Oliveira, I. B. (Orgs.). Sentidos de currículo: entre linhas teóricas, metodológicas e experiências investigativas. Campinas: FE/UNICAMP,2006a. p. 28-32.

. Decifrando o pergaminho - o cotidiano das escolas nas lógicas das redes cotidianas. In: Alves, N.; Oliveira, I. B. (Orgs.). Pesquisa no/do cotidiano das escolas: sobre redes de saberes. Rio de Janeiro: DP\&A, 2001. p. 13-38.

. Diversidade e currículo: questão ou solução? In: Alves, N.; VIllardi, R. (Orgs.). Múltiplas leituras da nova LDB. Rio de Janeiro: Dunya, 1997. p. 1-16.

. Educação e mídia: as tantas faces da professora "usuária" dos artefatos tecnológicos. In: Garcia, R. L.; Zaccur, E. (Orgs.). Cotidiano e diferentes saberes. Rio de Janeiro: DP\&A, 2006b. p. 223-231. 
Alves, N. Formação do jovem professor para a educação básica. Caderno CEDES, São Paulo, v. 17, p. 5-20, 1996a.

. Organização do trabalho na escola: formas convencionais e alternativas. In: Bicudo, M. A. V.; Silva Junior, C. A. da. (Orgs.). Formação do educador. São Paulo: UNESP, 1996b. p. 143-152.

. Redes educativas 'dentrofora' das escolas, exemplificadas pela formação de professores. In: SAnTos L. et al. (Orgs.). Convergências e tensões no campo da formação e do trabalho docente: Currículo, Ensino de Educação Física, Ensino de Geografia, Ensino de História, Escola, Família e Comunidade. Belo Horizonte: Autêntica, 2010. p. 49-66.

. Romper o cristal e envolvermo-nos nos acontecimentos que se dão: os contatos cotidianos com a tecnologia. In: LeIte, M.; Filé,J. V. (Orgs.). Subjetividade, tecnologias e escolas. Rio de Janeiro: DP\&A, 2002b. p. 15-26.

. Trajetórias e redes na formação de professores. Rio de Janeiro: DP\&A, 1998b.

. Valores-conhecimentos que organizam nossa identidade e nos levam à ação currículos, cotidianos e identidades. In: Moreira, A. F. et al. (Orgs.). Currículo e produção de identidades. Porto: Porto Ed., 2002c. p. 113-128.

Alves, N.; Garcia, R. L. A construção do conhecimento e o currículo dos cursos de formação de professores na vivência de um processo. In: Alves, N. (Org.). Formação de professores: pensar e fazer. 6. ed. São Paulo: Cortez, 2001. p. 73-88.

Certeau, M. de. A revolução do crível. In: . A cultura no plural. Campinas: Papiros, 1995. p. 23-40.

Dias, R. E.; Ponce, B. J. Dossiê ABdC - Formação Docente frente às políticas no cenário de centralização curricular. E-Curriculum, São Paulo, v. 13, n. 4, 2015.

Macedo, E.; Susserind, M.L. (Orgs.). Dossiê temático: debates em torno da ideia de bases curriculares nacionais. E-Curriculum, São Paulo, v. 12, n. 3, 2014.

Oliveira, I. B. Currículos e pesquisas com os cotidianos: o caráter emancipatório dos currículos 'pensadospraticados' pelos 'praticantespensantes' dos cotidianos das escolas. In: Ferraço, C. E.; Carvalho, J. M. (Orgs.). Currículos, pesquisas, conhecimentos eprodução de subjetividades. Petrópolis: DP\&A, 2012. p. 47-70.

Otranto, C.R.A nova LDB da Educação Nacional: seu trâmite no Congresso e as principais propostas de mudança. Revista Universidade Rural, Rio de Janeiro, v. 18, n. 1-2, dez. 1996.

\section{SOBRE A AUTORA}

Nilda Guimarães Alves é doutora em ciências da educação pela Université Paris Descartes (França). Pesquisadora convidada da Universidade do Estado do Rio de Janeiro (UERJ).

E-mail: nildag.alves@gmail.com 